\title{
Dukungan Ibu Kandung, Mertua dan Suami dengan Praktek Asi Eksklusif (0-6 Bulan) di Kampung Sereh Wilayah Puskesmas Sentani Papua
}

\author{
Aleda Florince oyay ${ }^{1}$, Agus Sartono ${ }^{2}$, Erma Handarsari ${ }^{3}$ \\ ${ }^{1,}$ RSUD Abepura Jayapura-Papua \\ ${ }^{2,3}$ Program Studi S1 Gizi Fakultas Ilmu Keperawatan dan Kesehatan \\ Universitas Muhammadiyah Semarang \\ ermahandarsari@gmail.com
}

\begin{abstract}
Health profil data of Jayapura Regency, Papua in 2014 is showed the scope of mother's milk-feeding only 40,28\%. It is increasing than in 2012 that only 28,78\%. It is showed that exclusive mother's milk-feeding program in Jayapura City is not success. Purpose of this study is for knowing relationship between the biological mother support, parent-in-law, and husband with exclusive mother's milk-feeding practice (0-6 months) in Kampung Sereh Wilaya Puskesmas Sentani Papua. This study is analytic applying retrospective approach with case control study design, samples of this study are 69 that determined by random, which is divided into 2 groups, those are, case group (exclusive mother's milk-feeding) and control group (not exclusive mother's milk-feeding). Method of collecting data is applying direct interview using questionnaire sheet. Statistical analysis used Chi-Square. There are significant relationship between support of biological mother support $(p=0,006)$, mother-in-law $(p=0,000)$, and husband $(p=0,007)$, on practice of exclusive mother's milk-feeding. Support of biological mother, mother-in-law, and husband has a good support on practice of exclusive mother's milk-feeding.
\end{abstract}

Keywords : Biological Mother, parent-in-law, husband, Exclusive Mother's Milk-feeding.

PENDAHULUAN

Kebutuhan zat gizi bagi bayi usia 0 sampai 6 bulan merupakan hal yang sangat penting diperhatikan oleh ibu. Pemberian ASI berarti memberikan makanan yang bernilai gizi tinggi yang dibutuhkan untuk pertumbuhan dan perkembangan syaraf dan otak bayi, memberikan zat-zat kekebalan terhadap beberapa penyakit dan mewujudkan ikatan emosional antara ibu dan bayinya (Depkes RI, 2009). Hasil penelitian mengungkapkan bahwa salah satu faktor dominan yang mempengaruhi Jurnal Gizi Vol 9 No 1 Tahun 2020 pemberian ASI Eksklusif adalah dukungan keluarga (Prawirodihardjo,2013). Dalam penelitian mengenai faktor yang berhubungan dengan pemberian ASI Eksklusif menyatakan bahwa dukungan keluarga menjadi faktor dominan yang berhubungan dengan pemberian ASI Eksklusif (Iradewi,2012). Hal senada diungkapkan pula oleh peneliti Biswas (2010),(Fauziel,(2007).Anggota keluaga yang dapat mempengaruhi pemberian ASI Eksklusif adalah orang tua, suami dan mertua dari ibu bayi (nenek). Peran nenek 
biasanya paling dominan diantara anggota keluarga lainnya (Suradi, et al,2010).

Cakupan ASI eksklusif di kota jayapura belum mencapai target $80 \%$. Data profil kesehatan kabupaten/kota di provinsi Papua tahun 2014 menunjukan cakupan ASI ekslusif 40,28\%. Terjadi peningkatan dibandingkan degan tahun 2012 yang baru mencapai $28,78 \%$. Hal ini menunjukkan bahwa program ASI esklusif di kota Jayapura belum berhasil. Hasil wawancara kepada 10 orang ibu menyusui tak eksklusif, 7 ibu diantaranya menyatakan tidak mendapatkan dukungan dari ibu kandung dan suami untuk menyusui bayinya.

\section{METODE PENELITIAN}

Jenis penelitian ini adalah Analitik dengan menggunakan pendekatan retrospektif dengan desain kasus kontrol. Pengambilan sampel ditentukan secara random dibagi menjadi 2 (dua) yaitu kelompok kasus dan kelompok kontrol. Kelompok kasus adalah kelompok ibu bayi yang memberikan ASI Eksklusif 41 sampel sedangkan kelompok kontrol adalah kelompok ibu bayi yang tidak memberikan ASI eksklusif, 28 sampel.

Penelitian dilakukan di kampung sereh wilayah puskesmas sentani papua, bulan Desember 2016 sampai Januari 2017. Data primer diperoleh dengan cara wawancara menggunakan kuesioner kepada responden,data primer mencakup dukungan ibu kandung,dukungan ibu mertua dan dukungan suami dengan praktek pemberian ASI eksklusif. Data sekunder adalah ibu menyusui yang mempunyai bayi $0-6$ bulan yang tercatat di kampung sereh wilayah puskesmas sentani papua sebanyak 69 responden. Cara pengumpulan data dengan wawancara pada ibu menyusui yang mempunyai bayi 0-6 bulan menggunakan lembar kuesioner dari responden yang sudah menjadi sampel Pengumpulan data di lakukan dengan memperhatikan aspek -aspek etika,lembar persetujuan,tanpa nama,kerahasiaan.

Instrumen yang digunakan dalam penelitian ini adalah lembar kuesioner dan lembar persetujuan (informed consent), sebelum menanyakan isi kuesioner terlebih dahulu peneliti memberikan /membagikan lembar persetujuan menjadi responden yang diisi langsung oleh responden,setelah responden bersedia /setuju kemudian memberikan pertanyaan sesuai dengan isi kuesioner. Analisis data yang diperoleh dari hasil pengumpulan data dan di bagi dalam kelompok kasus dan kelompok kontrol disajikan dalam bentuk tabel yang meliputi, umur, jenis kelamin, dukungan ibu kandung, dukungan mertua dan dukungan suami dan praktek pemberian ASI eksklusif. Analisis bivariat dilakukan pada variabel bebas dan terikat menggunakan Chi-Square dengan tingkat signifikan 
0,05.serta menghitung besar odd Ratio variabel bebas untuk mengetahui besar faktor resiko.

\section{HASIL DAN PEMBAHASAN}

\section{Gambaran umum Lokasi Penelitian}

Kampung Sereh adalah salah satu kampung yang terletak di Distrik Sentani wilayah Kabupaten Jayapura, memiliki luas wilayah 225,90 $\mathrm{km}^{2}$ dengan jumlah penduduk 45,679 jiwa. Kepadatan penduduk Kampung Sereh adalah 198,22 jiwa $/ \mathrm{km}^{2}$. Penduduk asli kampung sereh papua adalah suku sentani.

\section{Karateristik Responden}

Usia responden (bayi)

Usia bayi yang menjadi sampel penelitian secara lengkap dalam tabel 1 .

Tabel 1.Usia bayi yang menjadi sampel penelitian

\begin{tabular}{cccc}
\hline No & $\begin{array}{c}\text { Usia Bayi } \\
\text { (bulan) }\end{array}$ & n & $\begin{array}{c}\text { Jumlah Bayi } \\
\%\end{array}$ \\
\hline 1. & 1 & 17 & $24,6 \%$ \\
2. & 2 & 12 & $17,4 \%$ \\
3. & 3 & 15 & $21,7 \%$ \\
4. & 4 & 6 & $8,7 \%$ \\
5. & 5 & 8 & $11,6 \%$ \\
6. & 6 & 11 & $16 \%$ \\
\hline & Jumlah & 69 & 100 \\
\hline
\end{tabular}

Tabel 1 menunjukkan proporsi terbesar bayi yang menjadi sampel berumur 1 bulan dan proporsi terkecil berusia 4 bulan. Rata-rata umur bayi sampel adalah $3,13 \pm 1,869$ tahun.

Eksklusifitas menyusui berdasarkan usia bayi
Distribusi responden berdasarkan

eksklusifitas menyusui dan umur bayi secara lengkap disajikan dalam Tabel 2.

Tabel 2.Distribusi Responden Berdasarkan Eksklusifitas Menyusui dan Umur Bayi

\begin{tabular}{cccccc}
\hline & \multirow{2}{*}{$\begin{array}{c}\text { Umur } \\
\text { Bayi }\end{array}$} & \multicolumn{3}{c}{ Eksklusifitas Menyusui } \\
\cline { 3 - 6 } (bulan) & Eksklusif & \multicolumn{2}{c}{$\begin{array}{c}\text { Tdk Ek- } \\
\text { sklusif }\end{array}$} \\
\hline & & $\mathrm{n}$ & $\%$ & $\mathrm{n}$ & $\%$ \\
\hline 1. & 1 & 16 & 94,1 & 1 & 5,9 \\
2. & 2 & 10 & 83,3 & 2 & 6,7 \\
3. & 3 & 9 & 60 & 6 & 40 \\
4. & 4 & 4 & 66,7 & 2 & 33,3 \\
5. & 5 & 1 & 12,5 & 7 & 87,5 \\
6. & 6 & 1 & 9,1 & 10 & 90,9 \\
\hline & Total & 41 & 59,4 & 28 & 40.6 \\
\hline
\end{tabular}

Tabel 2 menunjukkan bahwa praktik ASI eksklusif di kampung sereh cukup tinggi, mencapai $59,4 \%$ tetapi lebih banyak terjadi pada umur-umur bayi muda, yaitu 1 sampai dengan umur 4 bulan.

\section{Jenis Kelamin Bayi (Sampel)}

Distribusi responden berdasarkan kasus kontrol dan jenis kelamin bayi dapat dilihat pada tabel 3.

Tabel 3.Distribusi Responden Berdasarkan KasusKontrol dan Jenis Kelamin Bayi

\begin{tabular}{lcccc}
\hline $\begin{array}{l}\text { Jenis } \\
\text { lamin }\end{array}$ & Ke- & \multicolumn{2}{c}{$\begin{array}{c}\text { Kelompok } \\
\text { Kasus }\end{array}$} & \multicolumn{2}{c}{$\begin{array}{c}\text { Kelompok } \\
\text { Kontrol }\end{array}$} \\
\cline { 2 - 5 } & $\mathbf{N}$ & $\mathbf{\%}$ & $\mathbf{n}$ & $\mathbf{\%}$ \\
\hline Perempuan & 23 & 56,1 & 19 & 67,9 \\
Laki-laki & 18 & 43,9 & 9 & 32,1 \\
\hline Jumlah & $\mathbf{4 1}$ & $\mathbf{1 0 0}$ & $\mathbf{2 8}$ & $\mathbf{1 0 0}$ \\
\hline
\end{tabular}

Hasil penelitian menunjukan bahwa lebih banyak bayi yang berjenis kelamin 
perempuan, baik pada kelompok kasus $(56,1 \%$ )maupun pada kelompok kontrol $(67,9 \%$.).

\section{Praktik pemberian ASI eksklusif}

Data Praktik pemberian ASI eksklusif diperoleh dari hasil wawancara langsung dengan responden, menggunakan kuesioner. Praktek pemberian ASI eksklusif di Kampung Sereh dapat dilihat pada tabel 4 .

Tabel 4. Praktik Pemberian ASI eksklusif di Kampung Sereh Papua

\begin{tabular}{lcc}
\hline Praktek Pemberian ASI & n & $\%$ \\
\hline & & \\
ASI eksklusif (kasus ) & 41 & $59,4 \%$ \\
$\begin{array}{l}\text { Tidak ASI eksklusif } \\
\text { (Kontrol) }\end{array}$ & 28 & $40,6 \%$ \\
\hline Jumlah & 69 & $100 \%$ \\
\hline
\end{tabular}

Hasil analisis menunjukkan bahwa sebagian besar $(59,4 \%)$ ibu menyusui di Kampung Sereh Papua, memberikan ASI eksklusif

\section{Dukungan ibu kandung}

Data dukungan ibu kandung di peroleh dari hasil wawancara dapat dilihat pada tabel .5.
Eksklusif di Kampung Sereh Papua

\begin{tabular}{lcccccc}
\hline $\begin{array}{c}\text { Dukungan } \\
\text { Ibu Kan- } \\
\text { dung }\end{array}$ & \multicolumn{6}{c}{ Praktek Menyusui } \\
\cline { 2 - 7 } & Eksklusif & $\begin{array}{c}\text { Tdk Ek- } \\
\text { sklusif }\end{array}$ & Jumlah \\
\hline $\begin{array}{l}\text { Dukungan } \\
\text { baik }\end{array}$ & 31 & 72,1 & 12 & 27,9 & 43 & 100 \\
$\begin{array}{c}\text { Dukungan } \\
\text { kurang }\end{array}$ & 10 & 27,8 & 16 & 72,2 & 26 & 100 \\
\hline Total & 41 & 59,4 & 28 & 40.6 & 69 & 100 \\
\hline \multicolumn{1}{c}{ Tabel } & 5 & menunjukkan & bahwa
\end{tabular}

sebagian besar ibu menyusui di Kampung Sereh Papua mendapatkan dukungan yang baik dari ibu kandung dalam hak memberikan ASI eksklusif Ibu menyusui yang mendapatkan dukungan baik dari ibu kandungnya, lebih banyak yang memberikan ASI eksklusif dibanding yang tidak mendapatkan dukungan baik dari ibu kandungnya.

Hal ini dapat dilihat bahwa ibu kandung tentu akan sangat sayang kepada anaknya yang sedang melahirkan cucunya sehingga pengalaman ketika ibu kandung melahirkan akan ditularkan kepada anaknya baik dalam merawat anak, memberikan contoh menyusui dan mengasuh anaknya. Ditunjang dengan kebudayaan masyarakat Papua dimana kaum perempuan apabila mempunyai bayi sering ditengok atau di jaga oleh ibunya.

Hasil penelitian ini sesuai dengan penelitian yang dilakukan oleh Sopiyani (2010) tentang hubungan antara dukungan sosial dengan motivasi memberikan ASI 
eksklusif di Kabupaten Klaten dengan hasil penelitian menunjukkan ada hubungan antara dukungan sosial dengan motivasi memberikan ASI eksklusifdi Kabupaten Klaten dengan nilai $p$ value $0,000(p<0,05)$.

\section{Dukungan Ibu Mertua}

Dukungan ibu mertua dapat di pada tabel 6.

Tabel 6 Dukungan Ibu Mertua Terhadap Praktik Pemberian ASI Eksklusif di Kampung Sereh Papua

\begin{tabular}{lcccccc}
\hline \multirow{2}{*}{$\begin{array}{l}\text { Dukungan } \\
\text { Ibu Mertua }\end{array}$} & \multicolumn{6}{c}{ Eksklusifitas Menyusui } \\
\cline { 2 - 7 } & Eksklusif & \multicolumn{2}{c}{$\begin{array}{c}\text { Tdk Ek- } \\
\text { sklusif }\end{array}$} & Jumlah \\
\hline & $\mathrm{n}$ & $\%$ & $\mathrm{n}$ & $\%$ & $\mathrm{n}$ & $\%$ \\
\hline $\begin{array}{l}\text { Dukungan } \\
\text { baik }\end{array}$ & 23 & 85,2 & 4 & 14,8 & 27 & 100 \\
$\begin{array}{l}\text { Dukungan } \\
\text { kurang }\end{array}$ & 18 & 42,9 & 24 & 57,1 & 42 & 100 \\
\hline \multicolumn{1}{c}{ Total } & 41 & 59,4 & 28 & 40.6 & 69 & 100 \\
\hline
\end{tabular}

Tabel 6 menunjukkan bahwa hanya $39,1 \%$ ibu menyusui di Kampung Sereh Papua mendapatkan dukungan yang baik dari ibu mertua mereka dalam hal memberikan ASI eksklusif. Ibu menyusui yang mendapatkan dukungan baik dari ibu mertuanya, lebih banyak yang memberikan ASI eksklusif dibanding yang tidak mendapatkan dukungan baik dari ibu mertuanya, yaitu 85,2\% dibanding 42,9\%. Dukungan mertua dapat meningkatkan praktek ASI eksklusif ibu menyusui.

Tradisi budaya masyarakat papua apabila anak mantunya melahirkan, mertua jarang ikut serta dalam melakukan pengasuhan kepada cucunya atau menantunya Sikap nenek atau nenek mertua terbukti berpengaruh pada praktek menyusui eksklusif pada ibu, hasil penelitian menyatakan bahwa sikap yang kurang positif akan memberikan risiko $60 \%$ lebih tinggi dalam mempengaruhi ibu untuk berhenti menyusui eksklusif dibandingkan sikap nenek yang lebih positif (Susiloretni K.A,2013).

Hasil penelitian ini sesuai dengan penelitian yang dilakukan oleh Siwi Kartika (2011) tentang Hubungan dukungan mertua dengan perilaku pemberian ASI Ekslusif di Puskesmas Sewon 1 Yogyakarta bulan Desember 2013 - Juli tahun 2014 dengan hasil penelitian menunjukkan bahwa hasil $p=0,040(p<0,05)$ yang berarti ada hubungan dukungan mertua dengan perilaku pemberian ASI Ekslusif di Puskesmas Sewon 1 Yogyakarta.

\section{Dukungan suami}

Data dukungan suami di dengan responden dapat dilihat pada tabel 7

\section{Tabel 7 Dukungan Suami Terhadap Praktik Pemberian ASI Eksklusif di Kampung Sereh Papua}

\begin{tabular}{ccccccc}
\hline \multirow{2}{*}{ Dukungan Suami } & \multicolumn{6}{c}{ Eksklusifitas Menyusui } \\
\cline { 2 - 7 } & Eksklusif & \multicolumn{1}{c}{$\begin{array}{c}\text { Tdk Ek- } \\
\text { sklusif }\end{array}$} & Jumlah \\
& $\mathrm{n}$ & $\%$ & $\mathrm{n}$ & $\%$ & $\mathrm{n}$ & $\%$ \\
\hline Dukungan baik & 32 & 71,1 & 13 & 28,9 & 45 & 100 \\
Dukungan kurang & 9 & 34,5 & 15 & 65,5 & 24 & 100 \\
\hline Total & 41 & 59,5 & 28 & 40.5 & 69 & 100 \\
\hline Tabel & 7 & menunjukkan & bahwa
\end{tabular}

sebagian besar ibu menyusui $(65,2 \%)$ di Kampung Sereh Papua mendapatkan 
dukungan yang baik dari suami mereka dalam hak memberikan ASI eksklusif. Ibu menyusui yang mendapatkan dukungan baik dari suaminya, lebih banyak yang memberikan ASI eksklusif dibanding yang tidak mendapatkan dukungan baik dari suaminya, yaitu $71,1 \%$ dibanding $34,5 \%$.

Dukungan suami dapat mempengaruhi kondisi psikis ibu. Keadaan emosi sangat mempengaruhi reflex pengaliran susu. Refleks ini mengontrol perintah yang dikirim oleh hipotalamus pada kelenjar bawah otak. Bila ibu sedang dalam kondisi stres, cemas, khawatir, tegang, dan sebagainya, air susu tidak akan turun dari alveoli menuju puting. Umumnya kejadian ini berlangsung pada hari-hari pertama menyusui dimana refleksi pengaliran susu belum sepenuhnya berfungsi.

Hasil penelitian ini sesuai dengan penelitian yang dilakukan oleh Sri Wahyuni (2008) tentang Hubungan pertolongan persalinan, dukungan keluarga, dan tingkat pendidikan ibu dengan pemberian kolostrum dan ASI eksklusif (studi di 9 desa IDT Kecamatan Bener Kabupaten Purworejo) dengan hasil penelitian menunjukkan Ada hubungan antara pertolongan persalinan, dukungan keluarga, dan tingkat pendidikan ibu dengan pemberian kolostrum dan ASI eksklusifdi 9 desa IDT Kecamatan Bener Kabupaten Purworejo)

\section{Hubungan dukungan ibu kandung dengan praktek ASI eksklusif}

Jurnal Gizi Vol 9 No 1 Tahun 2020
Hasil hubungan dukungan menunjukkan bahwa ibu menyusui di Kampung Sereh Papua yang mendapatkan dukungan baik dari ibu kandung sebagian besar memberikan ASI eksklusif, yaitu sebanyak 31 orang $(72,1 \%)$.Sebaliknya ibu menyusui yang mendapat dukungan kurang baik dari ibu kandung sebagian besar tidak memberikan ASI eksklusif, yaitu sebanyak 16 responden $(61,5 \%)$.

Hasil uji Chi Square, menghasilkan nilai $\mathrm{p}=0,006(<0.05)$ maka dapat disimpulkan ada hubungan yang bermakna antara dukungan ibu kandung dengan praktek ASI eksklusif.

Nilai Odd Rasio adalah 4,133. Hal ini menunjukkan dukungan ibu kandung yang baik dapat meningkatkan praktek ASI Eksklusif 4,133 kali lebih besar.

Menurut penelitian Diana (2007), ibu yang tinggal serumah dengan ibunya atau nenek mempunyai peluang sangat besar untuk memberikan MP-ASI dini pada bayi, bahkan ada ibu yang memberikan MPASI mulai bayi usia 11 hari atau setelah tali pusat lepas. Walaupun ibu mengetahui bahwa pemberian MP-ASI terlalu dini dapat mengganggu kesehatan bayi namun mereka beranggapan bahwa jika bayi tidak mengalami gangguan maka pemberian MPASI dapat dilanjutkan. Selain itu kebiasaan pemberian MP-ASI dini telah dilakukan turun-temurun dan tidak pernah menimbulkan masalah 


\section{Hubungan dukungan mertua dengan praktek ASI eksklusif}

Hubungan dukungan mertua dengan praktek ASI eksklusif ibu menyusui di Kampung Sereh Papua yang mendapatkan dukungan baik dari ibu mertua lebih kecil dibanding yang kurang mendapatkan dukungan dari ibu mertua, yaitu $39,1 \%$ dibanding $60,9 \%$. Namun demikian juga menunjukkan bahwa bagi ibu menyusui yang mendapatkan dukungan baik ibu mertua sebagian besar memberikan ASI eksklusif $(85,2 \%)$ sedang ibu menyusui yang kurang mendapat dukungan dari ibu mertua sebagian besar justru tidak memberikan ASI eksklusif $(57,1 \%)$.

Hasil Uji Chi Square, menghasilkan nilai $\mathrm{P}=0,000 \quad(<0.05)$ maka dapat disimpulkan ada hubungan yang bermakna antara dukungan ibu mertua dengan praktek ASI eksklusif. Nilai Odd,Rasio adalah 7,67. Hal ini menunjukkan dukungan ibu mertua yang baik dapat meningkatkan ketersediaan ASI Eksklusif 7,67 kali lebih besar. Hasil penelitian ini sesuai dengan penelitian yang dilakukan oleh Siwi Kartika (2011) tentang Hubungan dukungan mertua dengan perilaku pemberian ASI Ekslusif di Puskesmas Sewon 1 Yogyakarta bulan Desember 2013 - Juli tahun 2014 dengan hasil penelitian menunjukkan bahwa hasil p $=0,040$ $(\mathrm{p}<0,05)$ yang berarti ada hubungan dukungan mertua dengan perilaku pemberian ASI Ekslusif di Puskesmas Sewon 1 Yogyakarta.

\section{Hubungan Dukungan Suami Dengan Praktek ASI Eksklusif}

Hubungan dukungan suami dengan praktek ASI eksklusif menunjukkan bahwa ibu menyusui di Kampung Sereh Papua yang mendapatkan dukungan baik dari suami lebih besar dibanding yang kurang mendapatkan dukungan dari suami, yaitu $65,2 \%$ dibanding 34,8\%. Tabel 7 juga menunjukkan bahwa ibu menyusui yang mendapatkan dukungan baik dari suami sebagian besar memberikan ASI eksklusif $(71,1 \%)$ sedang ibu menyusui yang kurang mendapat dukungan dari suami 37,5\% yang memberikan ASI eksklusif.

Hasil Uji Chi Square menghasilkan nilai $\mathrm{p}=0,007(<0.05)$ maka dapat disimpulkan ada hubungan yang bermakna antara dukungan suami dengan praktek ASI eksklusif. Nilai Odd Ratio adalah 4,10. Hal ini menunjukkan dukungan suami yang baik dapat meningkatkan kesetersediaan ASI Eksklusif 4,10 kali lebih besar.Dukungan suami sangat penting dalam suksesnya menyusui, terutama untuk ASI eksklusif.

Hasil penelitian ini sesuai dengan penelitian yang dilakukan oleh Sopiyani (2010) tentang hubungan antara dukungan sosial dengan motivasi memberikan ASI eksklusif di Kabupaten Klaten dengan hasil 
penelitian menunjukkan ada hubungan antara dukungan sosial dengan motivasi memberikan ASI eksklusif di Kabupaten Klaten dengan nilai $p$ value $0,000(p<0,05)$.

\section{SIMPULAN DAN SARAN}

\section{Simpulan}

Dukungan ibu kandung, ibu mertua dan suami memiliki dukungan yang baik terhadap Praktek ASI eksklusif di Kampung Sereh Wilayah Puskesmas Sentani Papua.

\section{Saran}

1. Agar Puskesmas Sentani di Distrik sentani bekerjasama dengan PKK setempat untuk meningkatkan pendidikan gizi sehingga seluruh ibu kandung ,mertua dan suami memberikan dukungan positif 100\% pada ibu menyusui

2. Bagi ibu yang mempraktekkan ASI eksklusif agar dapat memotivasi ibuibu yang lain untuk praktek ASI eksklusif

\section{DAFTAR PUSTAKA}

Abdullah, dkk, 2004, Pengambilan Keputusan Pemberian ASI Eksklusif Kepada Bayi di Kota Bogor, Media Gizi \& Keluarga, Juli 2004

Afifah,Diana, 2007. Faktor-faktor yang Berperan dalam Kegagalan Praktik Pemberian ASI Eksklusif. Dibuka pada tanggal 23 September 2016 dari http://eprints.undip.ac.id

Biswas.(2010).Family Support on Exclusive Breastfeeding Practice among
Mother in Bangladesh. Thesis of submitted in Partial Fullfiment of the requirements for degree of master nursing science Prince of Songkla University. Diakses pada tanggal 21 September 2016.

Bobak, Irene M, 2009. Buku Ajar Keperawatan Maternitas.Jakarta. EGC.

Depkes RI., 2009. Pedoman Pemberian Makanan Bayi dan Anak, Jakarta: Depkes RI.

Dinkes. 2012. Profil Kesehatan Propinsi Papua tahun 2011. Kapubaten Jayapura

Ernawati, A. 2013. Pembangunan Kabupaten Pati. Seri Bunga Rampai. Pati: CV. Surya Grafika. 163-184.

Hendarto, A \& Pringgadini, K,. 2008 . Bedah ASI. Jakarta : Balai Penerbit FKUI. 